\title{
An Investigation into Perfectionism as a Moderator of the Links between Language Learning Styles and Strategies
}

\author{
Mansoor Fahim \\ English Department, Science and Research Branch, Islamic Azad University, Tehran, Iran \\ Rezvan Noormohammadi \\ English Department, Science and Research Branch, Islamic Azad University, Tehran, Iran
}

\begin{abstract}
Individual Differences in language learning, a topic whose complexity has meant little conclusive knowledge and thus needs for continuing inquiry (Ehrman, Leaver \& Oxford, 2003), was addressed in this study. Language learning perfectionism was investigated as an important and complicated educational construct related to important antecedents and consequences such as language learning styles and strategies. To promote successful language learning, the modifying roles of perfectionism in the relationship between language learning styles and strategies were emphasized. The study presented two kinds of data: quantitative and qualitative. In the quantitative study, the participants consisted of $265 \mathrm{EFL}$ second-year undergraduates. Three self-reported inventories, the Persian version of Learning Style Questionnaire (E\&L LSQ) (Ehrman \& Leaver, 2002); the Persian version of the Strategy Inventory for Language Learning (SILL) (Oxford, 1990); and the Persian version of Positive and Negative Perfectionism Scale (PANPS) (Terry-Short, Owens, Slade \& Dewey, 1995), were used. In the qualitative aspect of the study, semi-structured interviews have been performed among $34 \mathrm{high}$ and low achievers. The analyses indicated that positive perfectionism was more relevant factor attributing students' use of language learning strategies than styles. High achievers exhibited more positive perfectionism and absence of negative perfectionism, whereas low achievers exhibited signs of both positive and negative perfectionism. The pedagogical implications of the study were discussed.
\end{abstract}

Index Terms-positive perfectionism, negative perfectionism, synoptic style, ectenic style, language learning strategies

\section{INTRODUCTION}

The study of language learner characteristics or Individual Differences (IDs) and the degree to which they determine both the process and the product of foreign/ second language acquisition has been the object of interest in the field (Dornyei, 2005; Ehrman, 1996; Ellis, 2008; O'Malley \& Chamot, 1990; Oxford, 1990; Dornyei \& Skehan, 2003). Dornyei (2005) in his seminal book on the subject considers personality, motivation, language learning styles and strategies as the important learner characteristics.

To distinguish styles and strategies, Reid (1995) provides a standard definition for learning styles as: "an individual's natural, habitual, and preferred way(s) of absorbing, processing, and retaining new information and skills" (p. 121). Keefe (1979) also defines learning styles as "cognitive, affective and physiological behaviors that serve as relatively stable indicators of how learners perceive, interact with and respond to the learning environment" (p. 197). Cohen (1998), on the other hand, defines strategies as "learning processes which are consciously selected by the learner" (p. 162). Oxford (1999) offers a comprehensive and currently the best definition of language learning strategies as: "Specific actions, behaviors, steps, or techniques that students use to improve their own progress in developing skills in a second or foreign language" (p.163). To clarify the distinction between the two concepts, Sternberg and Grigorenko (2001) maintain, while styles work without individual awareness, strategies demand a conscious choice of alternatives.

However, this study seeks to extend the boundaries of individual differences discussed in foreign language learning and includes another important learner variable -most notably another personality trait- that is not normally discussed in the context of foreign language learning, namely perfectionism. The reason is that, in language courses in Iranian universities we can see students who fear making mistakes and focus on $10 \%$ of incorrect responses on an exam after receiving a grade of $90 \%$. These kinds of perfectionist students set excessively high standards and rigid rules for themselves, think in all-or-nothing pattern, satisfy hardly only if doing tasks without any margin of flaw, compare themselves with other students, evaluate themselves harshly, check excessively to ensure that everything is right, and procrastinate or delay activities to the last minutes (Burns, 1980; Hollender, 1978). In contrast, there are also students who set realistically high standards and flexible rules for themselves, aim to achieve their goals at the best of their ability, retain the ability to satisfy their performance, and tend to believe that success may occur at any moment (Hamachek, 1978; Slade \& Owens, 1998). 
An abundance of research studies on perfectionism most notably point toward its negative correlates. For instance, it was found that perfectionism positively correlates with depression (Flett, Besser, Hewitt \& Davis, 2007), neuroticism (Sumi \& Kanda, 2002) and personality disorders (Sassaroli et al., 2008) among other maladaptive and undesirable characteristics.

In L2 studies, Gregersen and Horwitz (2002) found the connection of 'anxiety specific to foreign language learning' with 'perfectionism'. They maintained that perfectionism can affect detrimentally language performance by increasing the anxiety associated with setting unrealistically high standards of performance, and fearing negative evaluations by others.

Recent conceptualizations of perfectionism, however, have involved dividing the construct into positive and negative components (Terry-Short, Owens, Slade \& Dewey, 1995). This implies that one form of perfectionism is robustly positive, normal and adaptable. According to Terry-Short et al. (1995) positive perfectionism involves "realistic and reasonable self expectations which accounted both for limitations and for strengths, with strivings accompanied by a sense of satisfaction and enhanced self-esteem" (p. 663). However, negative perfectionism involves "setting of unrealistically high targets, driven by a fear of failure, thought to originate in early environments of inconsistency and conditional positive approval" (Terry-Short, et al., p. 663).

In L2 studies, Swain and Burnaby (1976) examining personality traits important for success in French immersion programs, identified parents considered four loading factors: happiness, cheerfulness, talkativeness, and having a tendency toward perfectionism ( positive aspect) - however, only the last one, adaptive perfectionist tendencies, correlated significantly with L2 performance.

Given the importance of language learning styles, strategies, and perfectionism in the process of foreign language learning, this study seeks to find about the modifying roles of different types of perfectionism in the relation between styles and strategies. It tries to make aware both students and teachers to think more about what positive and negative perfectionism can do with students, how to manage students' perfectionism and help them overcome difficulties by applying appropriate strategies. The study also aims to make teachers more cognizant regarding the role of themselves in students' adoption of negative and positive dimensions of perfectionism in English language classes.

Accordingly, an attempt was made to find an empirically justified answer to each of the following questions:

1. Do perfectionism patterns make significant differences in students' use of language learning strategies?

2. Does positive perfectionism significantly modify the relationship between language learning styles and strategies?

3. Does negative perfectionism significantly modify the relationship between language learning styles and strategies?

4. What are the qualitative differences in language learning perfectionism between high achievers and low achievers?

To remain conservative, the researcher estimated null hypotheses for questions one to three. Question four is descriptive and does not pose any relation or interaction among variables. Hence, no hypothesis was stated for it.

\section{Methodology}

This study is a descriptive, mixed method study, having both quantitative phase and then follow-up qualitative semistructured interview phase. That is, the qualitative phase of the study was run to get greater insight about the differences of language learning perfectionism among high and low achievers. In the present study, styles were taken to be the independent variables and strategies were considered as dependent variables. Positive and negative perfectionism in learning language were taken as moderator variables, which is a special type of independent variable. That is, they have been selected as moderators to investigate whether they modify the relationship between the dependent and independent variables. To determine the significance of the statistical results of the study, the standard level of $\mathrm{p} \leq .05$ was considered.

\section{A. Participants}

A total of 265 EFL undergraduate Iranian university students studying General English as part of English for academic purposes in medical curriculum at Tehran University of Medical Sciences participated in this study. Students were randomly selected from medical fields of: speech therapy, audiometry, optometry, technical orthopedics, physiotherapy, occupational therapy, radiotherapy, surgical technology and laboratory science. They were sophomores and already passed two prerequisites English courses to be prepared for general and then academic English. The participants included 190 female and 75 male students, ranging in age from 18 to 25 (M=19.5, SD=.92). The group was not controlled for gender, age, or any other variables except the variables of the study.

Moreover, for the qualitative phase of the study, 34 sub-sample students were selected based on stratified sampling for in-depth study; branching questionnaires respondents into two groups of high achievers (n=17) and low achievers $(n=17)$. Students' reported scores on the objective questions of the final English test in the second semester of their first academic year were used as the indices of the students' language learning outcomes and the basis for their division in this study. The test items consisted of listening comprehension, reading comprehension, cloze and vocabulary, administered by English Center of Tehran University of Medical Sciences. The reliabilities of the final test scores ranged from .84 to .90 . In this study, those with the final score of 17-20 (out of 20) were considered as high achievers and those with the final score of 10-13 (out of 20) were considered as low achievers.

\section{B. Instrumentation}


Three paper-and-pencil instruments were used for the quantitative phase of the study as follow.

- Ehrman and Leaver Learning Style Questionnaire (E\&L LSQ)

It was developed by Ehrman and Leaver (2002). It contains 30 items using a 9- point semantic differential scale format and provides a rich set of data about an individual language learning styles which has the advantage of generality and specificity. This complex battery has an elaborate underlying theoretical construct and has undergone extensive field-testing and validation at the Foreign Service Institute. The instrument reorganizes a number of established style dimensions under a new, comprehensive construct with the two poles labeled Synopsis and Ectasis. The main difference between the two extremes is that a Synoptic learner allows more preconscious or unconscious processing whereas an Ectenic learner demands conscious control over the learning process. While synoptics tend to play their way through language learning, feel relaxed, and take risks, ectenics tend to be meticulous about language learning, dislike ambiguity, and safeguard themselves by avoiding tentative steps. The complete system is made up of 10 subdimensions as follow:

1: Field sensitivity_field insensitivity, 2: Field independence_field dependence, 3: Leveling-sharpening, 4: Globalparticular, 5: Impulsive-reflective, 6: Synthetic-analytic, 7: Analogue-digital, 8: Concrete-abstract, 9: Randomsequential, 10: Inductive-deductive.

This study, however, applied the general aspects of E\&L LSQ, namely Synoptic and Ectenic language learning style indices as predictors of achievement in the use of language learning strategies among university students. While, Synoptic pole included the first one of each opposing pair, ectenic pole included the second part of each pair. In this study, Cronbach alphas of .91and .92 were found for synoptic and ectenic styles respectively.

- Strategy Inventory for Language Learning (SILL)

It was developed by Oxford (1990). It contains a 50-item four-Point Likert-Scale ranging from 'never' to 'always' used to assess a broad range of L2 learning strategies. It measures the frequency with which a student uses memory, cognitive, compensation (under direct class), metacognitive, affective and social language learning strategies (under indirect class). The SILL is the best-known strategy scale and is utilized widely for its high reliability and validity. The internal consistency of SILL ranges from .89 to .98 in various studies (Oxford \& Burry-Stock, 1995). In this study Cronbach alpha found to be .93 for the Persian version of SILL.

- Positive and Negative Perfectionism Scale (PANPS)

It was developed by Terry-Short, Owens, Slade and Dewey (1995). It is a 40-item self-report inventory to assess the levels of Positive and Negative Perfectionism _two constructs that distinguish between _normal_ and _neurotic_ perfectionism. It is a five-point Likert type scale with anchors of strongly disagree, disagree, don't know, agree, and strongly agree. Scores for Positive Perfectionism (PP) and Negative Perfectionism (NP), each with 20 questions, can range from 20 to 100, with higher values indicating greater positive and negative perfectionism, respectively. TerryShort et al.(1995) reported evidence for construct validity of the scale, demonstrating that PANPS scores identified $86 \%$ of the eating disordered group.

In this study, based on Terry-Short et al. (1995) Positive and Negative Perfectionism Scale, a new Persian scale measuring these specific variables in language learning context was adapted. Cronbach alphas of .83 and .84 were obtained for positive and negative perfectionism in language learning respectively.

\section{Qualitative Interview Part of the Study}

Beside quantitative phase of the study, in qualitative part of the study, semi-structured interviews were performed branching questionnaires respondents into two groups of high achievers and low achievers. The interview dealt with the students' sense of perfectionism, whether they are completing their assignments to the end, and which pattern of perfectionism they are expressing. Sample questions are "does it suffice to study almost some materials or you need to learn it completely to the end?"; "Do you feel forced to reread what you read or you are comfortable reading it once? Please explain your experience."

\section{Procedure}

The coded batteries of the questionnaires were administered to 265 participants. Detailed instructions were given by the researcher on how to respond to the batteries. The purpose of the questionnaires and the potential significance of the results were communicated to the students. Further, the participants were guaranteed anonymity of their responses. It, actually, contributed to the honesty of respondents' answers. However, they were asked to keep the written code on the first page of the batteries of questionnaires for the follow up interview. Completing the coded packet of instruments typically required 45-50 minutes.

With consultation with experts in psychology and applied linguistics a careful planning of interview questions were made followed by some piloting, to ensure that the questions elicit sufficiently rich data and run smoothly. Again, in the process of the interview which took about 15 minutes for each student, the interviewees were told that the interviews would be highly confidential and used for research only. The interviews were audio taped and notes were taken on them for further analyses.

\section{RESULTS}


Normality of the data was checked by using Kolmogorov-Smirnov Test, run for the SILL, E\&L LSQ, and PANPS as presented in Table 1.

TABLE I.

MEANS, STANDARD DEVIATIONS AND KOLMOGROV-SMIRNOV INDICES FOR THE SUBSCALES OF

\begin{tabular}{|c|c|c|c|c|}
\hline Measure & $\mathrm{M}$ & SD & Kolmogorov-Smirnov Z & Sig. (2-tailed) \\
\hline \multicolumn{5}{|l|}{ SILL } \\
\hline Memory & 2.47 & .50 & .96 & .31 \\
\hline Cognitive & 2.42 & .47 & .89 & .39 \\
\hline Compensation & 2.31 & .55 & 1.50 & .06 \\
\hline Metacognitive & 2.79 & .58 & 1.31 & .06 \\
\hline Affective & 2.07 & .46 & 1.62 & .06 \\
\hline Social & 2.22 & .64 & 1.61 & .06 \\
\hline \multicolumn{5}{|l|}{ E\&L LSQ } \\
\hline Synoptic & 3.76 & .64 & 1.03 & .23 \\
\hline Ectenic & 3.47 & .67 & 1.29 & .70 \\
\hline \multicolumn{5}{|l|}{ PANPS } \\
\hline Positive Perfectionism & 3.95 & .48 & 1.14 & .14 \\
\hline Negative Perfectionism & 2.96 & .54 & .90 & .38 \\
\hline
\end{tabular}

Kolmogorov-Smirnov Test for the subscales of all three questionnaires indicated the sample of the study was distributed normally and was not found to be different from the population. Hence, parametric statistics were legitimately applied.

Concerning the descriptive statistics of the SILL, the mean of the individual strategy items ranged from 2.07 (for affective) to 2.79 (for metacognitive), with an overall mean of 2.42, indicating low (mean values between 1 and 2.4 ) strategy usage overall. As Phillips (1991) maintains, beginning L2 learners might possess little in declarative knowledge regarding their second language learning, and much less procedural knowledge about how to effectively apply learning strategies. Metacognitive strategies found to be the mostly applied ones $(\mathrm{M}=2.79)$ used by $52.5 \%$ of students with medium frequency. Among the other strategy categories, memory and cognitive strategies were also applied approximately in medium range, while compensation and social strategies were employed in low range, and affective strategies found to be the least used.

For the E\&L LSQ, the interplay of 10 bipolar dimensions of the scale made it possible for an individual to have both synoptic and ectenic tendencies, expressing more inclination toward one of them or adopting one as the dominant style. Thus, mean scores of both styles were calculated for the individuals in the sample. The participants reported higher preference for synoptic language learning style $(\mathrm{M}=3.76)$, indicating more interest toward subconscious processing or contextual learning of the language.

PANPS results generally indicated mean of 3.95 for positive perfectionism, which considered high (mean values between 3 and 5) and mean of 2.96 for negative perfectionism, which considered low (mean values between 1 and 3 ) among the students. Generally speaking, it could be considered a favorable sign, however, it would be analyzed in details while answering research question one of the study.

\section{A. Answer to Research Question One}

To answer the first research question of the study multivariate analysis of variance (MANOVA) was utilized to examine the differences among language learning strategies employed by learners with different patterns of language learning perfectionism. To specify different patterns of perfectionism, using a cutoff of mean score 3 ( $M=3$ ), students were allocated to four groups according to their response to PANPS: High Positive/High Negative (HP/HN), Low Positive/High Negative (LP/HN), High Positive/Low Negative (HP/LN), and Low Positive/Low Negative (LP/LN) perfectionism. Fig. 1 illustrates group classification of language learning perfectionism pattern.

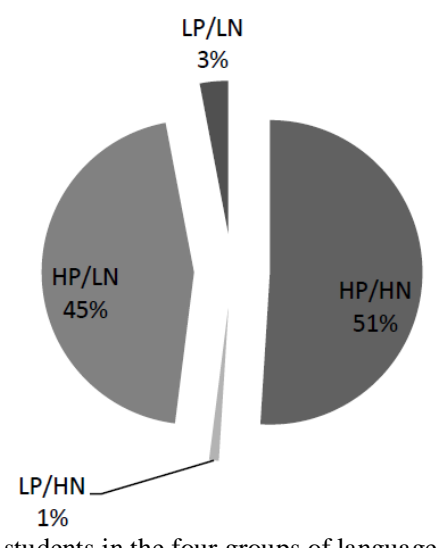

Figure 1: Percentage of students in the four groups of language learning perfectionism 
The findings of this study provided support for the presence of two major perfectionists groups in Iranian university students: HP/LN (adaptive) and HP/HN (maladaptive). The highest percentage of students had HP/HN pattern (51\%). In Terry-Short's et al. (1995) study, people with eating disorder had somehow this pattern of perfectionism. These were the ones who needed support to lower their negative aspect of perfectionism. They were prone to obsession-compulsion, procrastination and excessive expectation from themselves. In the present study, 45\% had HP but LN (adaptive) perfectionism. These were considered the happiest ones, mostly found among successful, athlete people in Terry-Short's et al. study. The lowest percentage in this study was for LP/HN (extreme case). These were found among depressed individuals in Terry-Short's et al. study, demanding clinical support. Non-perfectionists (LP/LN) or normal in TerryShort's et al. account just made $3 \%$ of the sample population in this study.

Table 2 presents numbers of students with different language perfectionism patterns, and the mean strategy use of the groups. The highest mean of strategies use found for HP/HN and HP/LN with different orchestrations.

TABLE II.

NUMBER OF STUDENTS IN EACH GROUP OF LANGUAGE PERFECTIONISM PATTERN AND THEIR PERFORMANCE ON SILL

\begin{tabular}{|c|c|c|c|c|c|c|c|c|c|c|c|c|c|}
\hline \multicolumn{2}{|c|}{ Language Perfectionism } & \multicolumn{12}{|c|}{ Dependent Strategies of SILL } \\
\hline \multirow[t]{2}{*}{ Pattern } & \multirow[t]{2}{*}{$\mathrm{N}$} & \multicolumn{2}{|c|}{ Memory } & \multicolumn{2}{|c|}{ Cognitive } & \multicolumn{2}{|c|}{ Compensation } & \multicolumn{2}{|c|}{ Metacognitive } & \multicolumn{2}{|c|}{ Affective } & \multicolumn{2}{|c|}{ Social } \\
\hline & & $\mathrm{M}$ & SD & $\mathrm{M}$ & $\mathrm{SD}$ & $\mathrm{M}$ & $\mathrm{SD}$ & M & SD & M & SD & M & $\mathrm{SD}$ \\
\hline $\mathrm{HP} / \mathrm{HN}$ & 136 & 2.49 & .51 & 2.37 & .47 & 2.22 & .54 & 2.74 & .60 & 2.09 & .47 & 2.19 & .67 \\
\hline $\mathrm{LP} / \mathrm{HN}$ & 2 & 2.27 & .39 & 1.78 & .30 & 1.67 & .70 & 2.28 & .70 & 2.17 & .00 & 1.16 & .56 \\
\hline HP/LN & 119 & 2.48 & .50 & 2.53 & .44 & 2.44 & .54 & 2.90 & .53 & 2.07 & .45 & 2.33 & .56 \\
\hline LP/LN & 8 & 2.08 & .32 & 1.92 & .33 & 2.02 & .42 & 2.19 & .47 & 1.58 & .30 & 1.36 & .26 \\
\hline
\end{tabular}

Since the numbers of students in the four groups of language perfectionism patterns were not approximately equal, Box's Test was run to check the assumption of homogeneity of covariances of the six dependent strategies across the four perfectionism groups. Box's test found not to be significant $(p=.56)$. Then, the assumption of equality of covariance matrices was not violated. To check for the equality of error variances across the six strategy groups Levene's test was also checked. However, except for social strategies $(p=.01)$ all the other variances found not to be significant. Given that the Box test was not significant and this was the only Levene test that was significant, the researcher was opting to conduct the analysis, but to use corrected follow-up test. In the corrected model, social strategies were found to be significantly differentiated among groups $(\mathrm{F}(3,261)=7.09, \mathrm{p}=.000)$. Test of betweensubjects effect that is analogous to perform four separate univariate one-way ANOVAs indicated significant Eta of .86 for social strategies which is considered great effect size. Dannett 3, a test for checking variables in which the assumption of homogeneity of variances was violated, also found to be significant for social, indicating significant differences in social strategies between each of HP/LN and HP/HN with LP/LN. In other words LP/LN significantly used this strategy lower than the other two prevalent groups. Further, HP/LN and HP/HN displayed no significant difference with each other for this strategy.

Then, a multivariate analysis of variance was conducted to examine whether the four language perfectionism patterns differed on a linear combination of the dependent variables of language learning strategies. A significant difference was found, Wilk's Lambda $=.84, \mathrm{~F}(256,724)=2.56, \mathrm{p}=.000$, multivariate $\eta^{2}=.05$ with medium effect size of .22 . Examination of the coefficients for the linear combinations distinguishing language perfectionism groups indicated that all six language strategies except memory contributed most to distinguishing the groups. HP/LN and HP/HN found to use memory significantly as high as each other. The roles of LP/HN and LP/LN groups of language perfectionism were not significant in the MANOVA analyses. Results of the parameter estimates of how the dependent variables of language strategies were weighted in the equation that maximally distinguished HP/HN (maladaptive) and HP/LN (adaptive) groups of language perfectionism patterns were synthesized into Table 3 in which values of Beta weights were demonstrated.

TABLE III.

DETAILS OF CONTRIBUTION OF LANGUAGE LEARNING STRATEGIES IN DISCRIMINATING HP/HN AND HP/LN GROUPS OF LANGUAGE LEARNING PERFECTIONISM

\begin{tabular}{l|l|l|l|l|l|l|l}
\hline Language & \multirow{2}{*}{$\begin{array}{l}\text { N } \\
\text { Perfectionism }\end{array}$} & & Dependent Language Learning Strategies & Cocial \\
\cline { 3 - 9 } & & Memory & Cognitive & Compensation & Metacognitive & Affective & $.83^{* * *}$ \\
\hline HP/HN & 136 & $.40^{*}$ & $.45^{* *}$ & .20 & $.55^{* *}$ & $.51^{* *}$ & $.93^{* * *}$ \\
\hline HP/LN & 119 & $.40^{*}$ & $.62^{* * *}$ & $.42^{*}$ & $.70^{* * *}$ & $.49^{* *}$ & \\
\hline
\end{tabular}

HP/LN group had the highest Beta weights for all strategies (except having equal weight in memory with HP/HN and lower weight in use of affective than that of $\mathrm{HP} / \mathrm{HN}$ ), discriminating this group from the other groups of perfectionism pattern. High positivity and low negativity of perfectionism allied this group of students to the full advantage of applying language strategies in their process of English learning.

Besides, HP/HN had also significant etas for just five strategy category (except compensation strategies), discriminating this group from the adaptive group of perfectionism pattern. Their high negative perfectionism could have blocked them to apply compensation Strategies. That is, they were not fortunate enough to overcome their limitations in speaking by circumlocution, or letting themselves to guess through compensation strategies. 


\section{B. Answer to Research Question Two}

To answer the second research question of the study, multiple regression was utilized to examine the modifying role of positive perfectionism in the association between language learning styles and strategies. To avoid multicolinearity between synoptic and ectenic language learning styles, separate regression analyses were utilized for the combination of each of synoptic and ectenic styles (independent variables) with the positive perfectionism. On the other hand, each of the six subscale scores from the SILL served as one criterion variable per regression analysis.

Table 4 presents results for multiple regression of synoptic and positive perfectionism for predicting SILL strategies.

TABLE IV.

\begin{tabular}{|c|c|c|c|c|c|c|}
\hline $\begin{array}{l}\text { Criterion Dependent } \\
\text { Variables }\end{array}$ & $\mathrm{R}$ & $\begin{array}{l}\text { Adjusted } \\
\mathrm{R}^{2}\end{array}$ & $\mathrm{~F}(2,262)$ & $\begin{array}{l}\text { Significant } \\
\text { Predictor }\end{array}$ & SEB & $\beta$ \\
\hline Memory & .38 & .14 & $22.67 * * *$ & PP & .06 & $.35 * * *$ \\
\hline Cognitive & .44 & .19 & $32.27 * * *$ & PP & .05 & $.43 * * *$ \\
\hline Compensation & .35 & .09 & $15.49 * * *$ & PP & .06 & $.32 * * *$ \\
\hline Metacognitive & .54 & .28 & $53.96 * * *$ & PP & .06 & $.52 * * *$ \\
\hline Affective & .39 & .15 & $24.40^{* * * *}$ & PP & .05 & $.39 * * *$ \\
\hline Social & .41 & .16 & $26.80^{* * * *}$ & PP & .07 & $.39 * * *$ \\
\hline
\end{tabular}

The results yielded six equations that were statistically significant. As indicated in Table 4, about $14 \%$ of the total variance in memory, $19 \%$ in cognitive, $9 \%$ in compensation, $28 \%$ in metacognitive, $15 \%$ in affective, and approximately $16 \%$ in the social strategy category was accounted for by the predictor variables. The observed regression coefficients $\mathrm{F}$ also indicated that the combination of synoptic and positive perfectionism significantly predicted the dependent strategy variables. However, the Standardized Beta Coefficients found to be significant only for positive perfectionism, meaning that only positive perfectionism significantly added anything to the prediction of final analysis. The highest weight of predicting strategies by positive perfectionism was found for metacognitive $(\beta=.52)$ (large effect size), then cognitive $(\beta=.43)$, affective and social $(\beta=.39)$, memory $(\beta=.35)$, and the least but still significant was for compensation strategies $(\beta=.32)$, ranged in large to medium effect sizes. The more the student benefited from positive perfectionism, the more s/he applied language learning strategies, specially, metacognitive strategies.

To investigate the association of ectenic and positive perfectionism for predicting SILL strategies, multiple regression was also conducted by entering both predictors simultaneously. The results are summarized in Table 5 .

TABLE V.

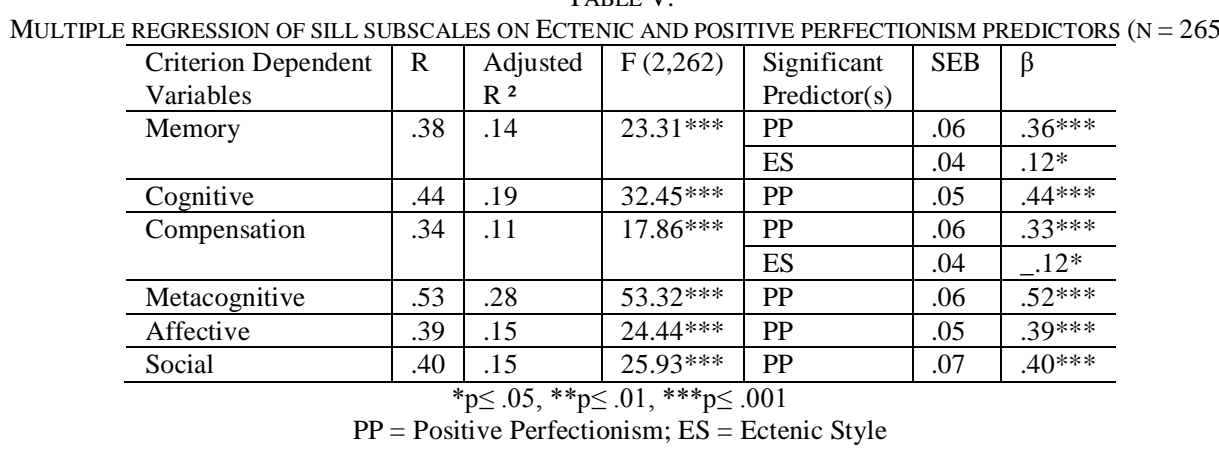

This time, again the results of the multiple regression analyses yielded six equations that were statistically signifycant. However, there found to be some changes comparing with that of synoptic and positive perfectionism (Table 4). The adjusted $\mathrm{R}$ square found to be approximately the same as the previous equations. However, the Standardized Beta Coefficients found to be significant not only for positive perfectionism but also for ectenic style in predicting memory and compensation strategies, but Betas for ectenic comparing to that of positive perfectionism had lower weights for these strategies (.12 and _.12 respectively). Here, the co-appearance of ectenic style with positive perfectionism in predicting memory and compensation strategies uncovered the fact that ectenic could not correlate as much as synoptic with this aspect of perfectionism, then appeared as significant predictor, however, with lesser weight and even negative weight in the final analysis. The interesting point was that ectenic negatively predicted compensation strategies. The higher the student possessed ectenic style, the lower s/he made use of compensation strategies. For other strategies it was still only positive perfectionsm that significantly added anything to the prediction of final analysis. The rank order of beta weights for positive perfectionism predicting strategies found to be the same as the previous model. To reiterate, the more the student benefited from positive perfectionism, the more s/he applied language learning strategies.

\section{Answer to Research Question Three}


To answer the third research question of the study, like previous question, multiple regression was utilized to examine the modifying role of negative perfectionism in the association between language learning styles and strategies. Likewise, separate multiple regression analyses were utilized for the combination of each of synoptic and ectenic styles with the negative perfectionism for prediction of the six language learning strategies.

Table 6 presents the results for multiple regression of synoptic and negative perfectionism for predicting SILL strategies.

TABLE VI.

MULTIPLE REGRESSION OF SILL SUBSCALES ON SYNOPTIC AND NEGATIVE PERFECTIONISM PREDICTORS $(\mathrm{N}=265)$

\begin{tabular}{l|l|l|l|l|l|l}
\hline $\begin{array}{l}\text { Criterion Dependent } \\
\text { Variables }\end{array}$ & $\mathrm{R}$ & $\begin{array}{l}\text { Adjusted } \\
\mathrm{R}^{2}\end{array}$ & $\begin{array}{l}\mathrm{F}(2,262) \\
\text { Predictor }\end{array}$ & Significant & SEB & $\beta$ \\
\hline Memory & .17 & .02 & $4.30^{*}$ & SS & .04 & $.14^{*}$ \\
\hline Cognitive & .14 & .01 & 2.90 & - & - & - \\
\hline Compensation & .18 & .02 & $4.70^{* *}$ & NP & .06 & $-.18^{* *}$ \\
\hline Metacognitive & .16 & .01 & $3.58^{*}$ & SS & .05 & $.15^{* *}$ \\
\hline Affective & .13 & .00 & 2.26 & - & - & - \\
\hline Social & .12 & .00 & 1.94 & - & - & - \\
\hline \multicolumn{7}{c|}{${ }^{*} \mathrm{p} \leq .05, *{ }^{*} \mathrm{p} \leq .01$}
\end{tabular}

$\mathrm{NP}=$ Negative Perfectionism; SS = Synoptic Style

The results of the multiple regression analyses yielded just three statistically significant equations. As indicated in Table 6 , just $2 \%$ of the total variance in memory, $1 \%$ in cognitive, $2 \%$ in compensation, $1 \%$ in metacognitive, and approximately nothing in affective and social strategy categories were accounted for by the predictor variables. The observed regression coefficients $\mathrm{F}$ indicated that the combination of synoptic and negative perfectionism significantly predicted just memory, compensation and metacognitive strategies. For predicting both memory and metacognitive strategies the Beta Coefficient found to be significant only for synoptic style, meaning that it was just synoptic style that significantly added anything to the prediction of these strategies. On the other hand, the Standardized Beta Coefficients in predicting compensation strategies found to be significant only for negative perfectionism, meaning that only negative perfectionism significantly added anything to the prediction of compensation strategies. However, the variance in compensation strategies negatively accounted by negative perfectionism or negativity in perfectionism made one use less compensation strategies. In all, in contrast to positive perfectionism that along with synoptic style significantly predicted application of all six strategies, negative perfectionism just displayed itself along with synoptic style, in just one negatively significant prediction (that of compensation strategies). As a result, negative perfectionism did not help at all in strategy use.

Further, to investigate the association of ectenic and negative perfectionism for predicting SILL strategies, multiple regression was also conducted by entering both predictors simultaneously. The results are summarized in Table 7.

TABLE VII.

MULTIPLE REGRESSION OF SILL SUBSCALES ON ECTENIC AND NEGATIVE PERFECTIONISM PREDICTORS $(\mathrm{N}=265)$

\begin{tabular}{l|l|l|l|l|l|l}
\hline $\begin{array}{l}\text { Criterion Dependent } \\
\text { Variables }\end{array}$ & $\mathrm{R}$ & $\begin{array}{l}\text { Adjusted } \\
\mathrm{R}^{2}\end{array}$ & $\mathrm{~F}(2,262)$ & $\begin{array}{l}\text { Significant } \\
\text { Predictor }\end{array}$ & SEB & $\beta$ \\
\hline Memory & .17 & .02 & $3.98^{*}$ & $\mathrm{ES}$ & .04 & $.13^{*}$ \\
\hline Cognitive & .10 & .00 & 1.52 & - & - & - \\
\hline Compensation & .18 & .02 & $4.86^{* *}$ & $\mathrm{NP}$ & .06 & $\ldots .16^{* *}$ \\
\hline Metacognitive & .13 & .01 & $2.43^{*}$ & $\mathrm{ES}$ & .06 & $.13^{*}$ \\
\hline Affective & .12 & .00 & 1.92 & - & .05 & - \\
\hline Social & .06 &. .00 & .51 & - & .07 & - \\
\hline \multicolumn{7}{c}{${ }^{*} \mathrm{p} \leq .05, * * \mathrm{p} \leq .01$}
\end{tabular}

$\mathrm{NP}=$ Negative Perfectionism; ES = Ectenic Style

The results of the multiple regression analyses like those of the previous analyses for synoptic style yielded just three statistically significant equations. However, again, it was the significant role of the style (this time, ectenic) for predicting both memory and metacognitive strategies that beta found to be significant. But, here, the beta weights $(\beta$ $=.13$ for both strategies) found to be lower than those with synoptic styles, meaning that ectenic like synoptic had determining role in adopting both memory and metacognitive strategies but when co-occurring with negative perfectionism with lesser weight than that of synoptic style. Once more the Standardized Beta Coefficients in predicting compensation strategies found to be negatively significant only for negative perfectionism, meaning that negative perfectionism significantly added anything to the prediction of compensation strategies $(\beta=\ldots .16$, this time with lower weight than the previous analysis with synoptic style, $\beta=\ldots .18$ ). Altogether, in contrast to positive perfectionism that significantly predicted application of all six strategies, negative perfectionism just significantly predicted compensation strategies with negative loading.

As a result, self criticism that was associated with negative perfectionism at the best did not contribute to the use of strategies and at the worst came with serious costs in down changing strategy use. Clearly, in learning foreign language it would be desirable to have higher levels of positive perfectionism and lower levels of negative perfectionism. The core of the problem was that when a person's self worth depended on reaching excessively high standards, it was an 
inevitable script for self defeat and repeated failure, as the lower use of strategies end with lower achievement in language learning.

\section{Qualitative Differences in Language Learning Perfectionism between High Achievers and Low Achievers}

To answer the fourth research question of the study the interview data were analyzed according to comments related to positive and negative perfectionism.

$94 \%$ of high achievers reported they opted to read their assignments completely to the end rather than reading some materials, indicating their interest to do the tasks positively and completely rather than haphazardly. However, only $57 \%$ of low achievers reported their interest in completing their assignments.

While $58 \%$ of high achievers did not feel forced to go over a work assignment many times, the same numbers of students among low achievers expressed they felt forced to check their assignment excessively, indicating the negative aspect of perfectionism.

In the meantime, in response to the question: "are you glad to make efforts in learning language or you are concerned most of the time?" $94 \%$ of high achievers found to be highly positive perfectionists with approximately no degree of negative perfectionism, whereas $57 \%$ of low achievers found to have positive perfectionism and $42 \%$ had negative perfectionism.

The interview results of the perfectionism type of the high and low achievers were compatible with their quantitative statistics in which all the high achievers were HP/LN or adaptive perfectionists, while among low achievers there found to be two mixed groups of $\mathrm{HP} / \mathrm{HN}=$ maladaptive $(52 \%)$ and $\mathrm{HP} / \mathrm{LN}=$ adaptive $(47 \%)$ perfectionism. Further, the ratio of positive perfectionism to negative perfectionism was more for high achievers (2) than that of low achievers (1.26). Fortunately, for low achievers also the ratio of positive to negative perfectionism was more than the ratio of negative to positive. High negative perfectionism of $52 \%$ of low achievers (with HP/HN perfectionism), clearly, could be a major obstacle for their success in learning language. However, the other $47 \%$ with HP/LN among low achiever could represent those who did not try hard due to low interest and obligatory English course as expressed in the interview. Then, while the major pattern of perfectionism among high achievers found to be HP/LN (adaptive), it was HP/HN (maladaptive) for low achievers. Moreover, qualitatively speaking, high achievers were positive perfectionists since they felt deep personal satisfaction in learning language, while low achievers' positive perfectionism was fueled by the 'need' and 'obligation' behind learning language. It could be corroborated by the interview comments of members of these two groups as a high achiever mentioned: "when I feel tired, I study English to feel relaxed" and two other high achievers expressed their interest not just in learning English but also in learning other languages such as German, Spanish and Indian. On the other hand, a low achiever reported: "I dislike language, because other students outperformed me!". Participants from this group accounted for their negative perfectionism in learning language as fear of exam and the difficulty of the English conversation in the classroom: "I know that someday, I would be a disaster in learning language".

All the high achievers expressed their interest for being an absolutely excellent speaker of English. In the meantime, low achievers were also interested in speaking English excellently, but there were signs of despair in their accounts: "I do my best, but if I fail, I get depressed"; "I'd like to be the best in speaking English, but I fear and don't know how".

Further, all the high achievers, stated their great interest in comprehending English completely. The story was the same for low achievers, but again with some vein of discouragement: "only when I know how to do it well". Therefore, their negative perfectionism accompanying their ignorance of their language learning styles and strategies could have hindered their achievement.

Interestingly, $82 \%$ of high achievers in response to the question of "how do you feel, if you could not speak English faultlessly in the classroom?" reported they still feel relaxed, confident, hopeful and proud since "it's my right"; "I let myself to make mistake to learn language". But, $71 \%$ of low achieves identified feeling of inferiority, hate, fear, weakness, worry, dumbness, stupidity and lack of self confidence, "I feel nervous when speaking English", "I feel bad in my mind, I wonder why I can't speak English very well".

$88 \%$ of high achievers in response to the question of "how do you feel, if you could not understand all the points in the classroom?" stated they were letting themselves to guess; they would not lose their hope and ask their doubt from the teacher or other friends to make it clear. On the other hand, $71 \%$ of low achievers expressed their negative feeling in this regard, maintaining: "I get nervy"; "it's the worst experience in my life!"; "I feel I waste my time", "I feel I'm a poor learner".

Finally, students in both groups were asked to record the grade they received on actual exam in their last semester. The mean grade reported by the high achievers for the actual exam was 18.5 out of 20 . However, this grade for low achieves was 11.46 out of 20. Further, students in both groups were also asked to predict or to self-rate the grade they conceive they would receive for their final exam in the present semester. The mean self-rated grade reported by the high achievers found to be 19.29. However, that of low achieves found to be 17.14. This suggested that evidently, although the mean self-rated scores were higher for both groups, due to their positive perfectionism, the mean self rated score of low achievers found to be unexpectedly high, due to their negative perfectionism through which they set unattainably high standards for themselves. Subtracting the mean self-rated marks from the last semester actual mean marks for each group shed light on the issue (.79 for high achievers, and 5.68 for low achievers!). 
TABLE VIII.

MEANS OF REPORTED ACTUAL GRADES AND PERCEIVED GRADES FOR BOTH GROUPS OF HIGH ACHIEVERS $(\mathrm{N}=17)$ AND LOW ACHIEVERS $(\mathrm{N}=17)$

\begin{tabular}{l|l|l}
\hline & $\begin{array}{l}\text { Mean of } \\
\text { Actual Grade }\end{array}$ & $\begin{array}{l}\text { Mean of } \\
\text { Perceived Grade }\end{array}$ \\
\hline High Achievers & 18.5 & 19.29 \\
\hline Low Achievers & 11.46 & 17.14 \\
\hline
\end{tabular}

\section{DISCUSSION}

One purpose of this study was to examine the effect of different patterns of language learning perfectionism in the adoption of different strategy choices. MANONA analyzing all four groups of language perfectionism found to be significant, and two prominent patterns namely HP/LN and HP/HN found to be representative of Iranian students. Consequently, the first null hypothesis of the study was rejected for HP/LN and HP/HN perfectionism, indicating these types of perfectionism made significant differences in use of language learning strategies (except non significant application of compensation strategies by HP/HN). The significant value, at which the first null hypothesis of the study was rejected $p=.000$ revealed the importance of both HP/LN and HP/HN in effective strategy use. On the other hand, the first null hypothesis of the study was maintained for LP/HN and LP/LN perfectionism, indicating these types of perfectionism made no significant differences in use of language learning strategies or they found not to be determinants in use of strategies. However, beta weights for the two conspicuous patterns of perfectionism clearly indicated the superiority of HP/LN specifically by applying compensation strategies. In other words, the major hurdle of $\mathrm{HP} / \mathrm{HN}$ was their shunning compensation strategies. Hence, guessing intelligently and circumlocution found to be the ways to escape the capture of negative aspect of perfectionism for HP/HN perfectionists. Interestingly, these sorts of strategies revealed to be in the service of good language learning as suggested by oxford (1990).

The modifying roles of each positive and negative perfectionism in the association of language learning styles and strategies were also analyzed leading to the rejection of the second null hypothesis of the study, indicating that positive perfectionism significantly modified the relationship between language learning styles and strategies in a positive fashion. In contrast, the third null hypothesis of the study regarding negative perfectionism, was rejected only with regard to compensation strategies, indicating negative perfectionism significantly modified the relationship between language learning styles with compensation strategies in negative fashion. However, this null hypothesis was maintained with regard to other strategies, indicating negative perfectionism did not significantly modify the relationship between language learning styles with other strategies.

The findings found to be in line with Gregersen and Horwitz's (2002) study that regarded perfectionism (negative aspect) to affect detrimentally language performance by increasing the anxiety associated with L2 learning settings. As revealed, however, some form of perfectionism represented a robust positive disposition (Terry- Short, et al., 1995) and it could be unwise to consider perfectionism in any form to be maladaptive. Then, the findings also corroborated Swain and Burnaby's (1976) study that identified a tendency toward adaptive perfectionism as an important factor significantly correlated with L2 performance success in French immersion programs. It could be also inferred that negative perfectionism might terribly accompany debilitative anxiety, whereas positive perfectionism might conclusively accompany facilitative anxiety in language learning.

Qualitative differences between high achievers and low achievers in this study helped to the realization that, unlike high achievers, low achievers possessed veins of negative perfectionism as well as positive perfectioinism. It evidenced Frost et al.'s (1990) notion of perfectionistic concerns among low achievers that made language learning process miserable for them by expecting to speak flawlessly, with no grammar or pronunciation errors, and as easily as an L1. So, it is up to teachers to identify the signs of negative perfectionism in the learners and work to explore their earlier belief systems in order to help them.

\section{Conclusion}

The major findings presented in this study on the modifying roles of perfectionism in the relationship between language learning styles and strategies are as follow:

1. Some perfectionism patterns make significant differences in use of language learning strategies, in that, while, both HP/LN (adaptive) and HP/HN (maladaptive) perfectionism contribute to the employment of language learning strategies, LP/HN (extreme case) and LP/LN (non-perfectionist) have no contribution. Although, HP/LN and HP/HN are equally significant in use of memory strategies, HP/LN outweighs by causing application of more language learning strategies and particularly significant employment of compensation strategies.

2. Positive perfectionism positively modifies the relationship between language learning styles and strategies. It is more relevant factor attributing students' language learning strategies than styles.

3. Negative perfectionism negatively modifies the relationship between language learning styles and compensation strategies. It has no significant role for other strategies.

4. High achievers contrast with low achievers in that high achievers exhibit more positive perfectionism and absence of negative perfectionism, but low achievers exhibit signs of both positive and negative perfectionism. 
The research findings indicate that the interactive effects of language learning styles with language learning perfectionism usher in more insight in foreign language learning process or the adoption of language learning strategies. It is important to note that perfectionism can do more than make language learning unpleasant. Positive perfectionism, a desire to learn and discover new things and concepts is perceived as driving force behind success in second language learning. It is understood as an enjoyable effort to do one's best and an optimistic aspire to do better. Accompanying each of language learning styles, it still gives students credit for what they have accomplished while looking forward to new challenges and opportunities in applying language learning strategies. However, negative perfectionism can be counter-productive, as winning and infallibility may be considered the only reasons for getting rigid results. Accompanying each of language learning styles, it brings discredit on what students have desperately tried while running into more difficulties in use of language learning strategies, particularly in use of compensation strategies. Then, it is highly recommended that teachers stimulate negative perfectionists to practice compensation strategies through guessing intelligently in listening and reading, and overcoming limitations by circumlocution or using simple words in speaking and writing.

Finally, since a friendly and supportive learning environment is believed to facilitate learning of the foreign language, encouraging a not highly competitive learning situation by styles and strategies awareness raising is more important than quantitative summative evaluation of students. Thus, teachers are advised to implement intervention strategies targeted for maladaptive perfectionists; these may include identifying and correcting irrational and rigid beliefs about language learning (e. g. fear of making mistakes, self-criticism, excessive expectation), and encouraging students to take risks in learning language by particular use of compensation strategies.

\section{REFERENCES}

[1] Burns, D. D. (1980). The perfectionist's script for self-defeat. Psychology Today 14.6, 34-52.

[2] Cohen, A. D. (1998). Strategies in learning and using a second language. Harlow: Longman.

[3] Dornyei, Z. (2005). The psychology of the language learner: Individual differences in second language acquisition. New Jersey: Lawrence Erlbaum Associates.

[4] Dornyei, Z., \& Skehan, P. (2003). Individual differences in second language learning. In C.J. Doughty \& M.H. Long (Eds.), The handbook of second language acquisition. New York: Blackwell, 589-630.

[5] Ehrman, M. E. (1996). Understanding second language learning difficulties. London: Sage Publications.

[6] Ehrman, M. E., \& Leaver, B. L. (2002). E \& L learning style questionnaire v. 2.0. http://www.cup.es/resources/0521837510/2127_Leaver\%20learning\%20styles\%20test.DOC (accessed 1/1/2011).

[7] Ehrman, M. E., Leaver, B. L., \& Oxford, R. L. (2003). A brief overview of individual differences in second language learning. System 31, 313-330.

[8] Ellis, R. (2008). The study of second language acquisition (2nd ed.). Oxford: OUP.

[9] Flett, G. L., Besser, A., Hewitt, P. L., Davis, R. A. (2007). Perfectionism, silencing the self, and depression. Personality and Individual Differences 43, 1211-1222.

[10] Frost, R. O., Marten, P., Lahart, C., \& Rosenblate, R. (1990). The dimensions of perfectionism. Cognitive Therapy and Research 14, 449-468.

[11] Gregersen, T., \&. Horwitz, E. K. (2002). Language learning and perfectionism: Anxious and non-anxious language learners' reactions to their own oral Performance. The Modern Language Journal 86.4, 562-570.

[12] Hamachek, D. E. (1978). Psychodynamics of normal and neurotic perfectionism. Psychology: A Journal of Human Behavior 15, 27-33.

[13] Hollender, M. H. (1978). Perfectionism, a neglected personality trait. Journal of Clinical Psychiatry 39, 384-394.

[14] Keefe, J. W. (1979). Learning style: An overview. In J. W. Keefe (Ed.), Student learning styles: Diagnosing and prescribing programs. Reston, VA: National Association of Secondary School Principals, 1-17.

[15] Kramer, H. J. (1988). Anxiety, perfectionism and attributions for failure in gifted and non-gifted junior high school students. Dissertation abstract. U.S.A.: UMI.

[16] Oxford, R. L. (1990). Language learning strategies: What every teacher should know. Rowley, Mass.: Newbury House Publishers.

[17] Oxford, R. L. (1999). Learning strategies. In B. Spolsky (Ed.), Concise encyclopedia of educational linguistics. Oxford: Elsevier, 518-522.

[18] Oxford, R. L., \& Burry-Stock, J. (1995). Assessing the use of language learning strategies worldwide with the SSL/EFL version of the strategy inventory for language learning (SILL). System 23.1, 1-23.

[19] O'Malley, J. M., \& Chamot, A.U. (1990). Learning strategies in second language acquisition. Cambridge: CUP.

[20] Phillips, V. (1991). A look at learner strategy use and ESL proficiency. CATESOL Journal 4, 57-67.

[21] Reid, J. M. (Ed.). (1995). Learning styles in the ESL/EFL classroom. Boston: Heinle and Heinle.

[22] Sassaroli, S., Lauro, L. J. R., Ruggiero, G. M., Mauri, M. C., Vinai, P., \& Frost, R. (2008). Perfectionism in depression, obsessive-compulsive disorder and eating disorders. Behaviour Research and Therapy 46, 757-765.

[23] Slade, P. D., \& Owens, R. G. (1998). A dual process model of perfectionism based on reinforcement theory. Behavior Modification 22, 372-390.

[24] Sternberg, R. J., \& Grigorenko, E. L. (2001). A capsule history of theory and research on styles. In R. J. Sternberg \& L.F. Zhang (Eds.), Perspectives on thinking, learning, and cognitive styles. Mahwah, NJ: Lawrence Erlbaum Associates, 1-21.

[25] Sumi, K., \& Kanda, K. (2002). Relationship between neurotic perfectionism, depression, anxiety, and psychosomatic symptoms: a prospective study among Japanese men. Personality and Individual Differences 32, 817-826. 
[26] Swain, M., \& Burnaby, B. (1976). Personality characteristics and second language learning in young children: A pilot study. Working Papers on Bilingualism 11, 116-128.

[27] Terry-Short, L. A., Owens, R. G., Slade, P. D., \& Dewey, M. E. (1995). Positive and negative perfectionism. Personality and Individual Differences 18, 663-668.

Mansoor Fahim was a member of the faculty of English Language and Literature at Allameh Tabataba'i University in Tehran, Iran from 1981 to 2008 when he was retired as an associate professor of TEFL. He has taught English at a welter of universities. At present, he runs Research methods, Psycholinguistics, Applied Linguistics, Second Language Acquisition, and Seminar classes at M.A. level and First Language Acquisition, Psycholinguistics, and Discourse Analysis courses at Ph.D. level at a number of universities including Allameh Tabataba'i and Islamic Azad Universities. Moreover, he has several published articles and books mostly in the field of TEFL and has translated some books into Persian. Dr. Fahim is currently a member of the editorial board of some Iranian journals of Applied Linguistic Studies.

Rezvan Noormohammadi is a Ph.D. candidate of TEFL at Islamic Azad University, Science and Research Branch, Tehran, Iran. She received her M.A. degree from Tehran University in TEFL in 2000. She has taught English courses at Tehran University of Medical Sciences since 2000. She has published papers on TEFL in both foreign and local journals. Her interest is in psychological aspects of language learning and teaching, psycholinguistics, and second language acquisition. 